\title{
O papel da Feira de Ciências como estratégia motivadora para o ensino de Botânica na educação básica
}

Francisco Yago Elias de Castro Dias ${ }^{1}$, (1) Rafael Domingos de Oliveira ${ }^{2}$, (1) Roselita Maria de Souza Mendes ${ }^{3}$, (D) Lydia Dayanne Maia Pantoja ${ }^{3}$, (1) Oriel Herrera Bonilla ${ }^{3}$ e (D) Bruno Edson-Chaves ${ }^{4,5,6}$

Recebido: 16.05.2019; aceito: 09.03.2020

Como citar: Dias, F.Y.E.C., Oliveira, R.D., Mendes, R.M.S., Pantoja, L.D.M., Bonilla, O.H. \& Edson-Chaves, B. 2020. O papel da Feira de Ciências como estratégia motivadora para o ensino de Botânica na educação básica. Hoehnea 47: e552019. http://dx.doi.org/10.1590/2236-8906-55/2019

ABSTRACT - (The role of the Science Fair as a motivating strategy for teaching Botany in basic education). Botany teaching is marked by numerous problems, among them is the lack of methodologies to generate motivation in students. Thus, it was offered to the students of the subjects of Botany in Biological Sciences degree at the Universidade Estadual do Ceará to prepare teaching materials to compose a science fair, with only botanical content. The objective was to evaluate this alternative strategy and conceptual map as motivating factors for teaching botany. The fair took place in a school of the public network of Fortaleza, Ceará State, Brazil, with participation of students from $9^{\text {th }}$ grade to $3^{\text {rd }}$ year of high school. After the fair, a questionnaire was applied to students. It was realized that teaching strategies as the science fair require a number of factors that enable it to occur successfully, including the availability of resources and the time for performing it. Therefore, it was verified that this teaching strategy is a valuable tool that arouses students' interest for the subjects and it may serve to complement traditional exhibition methodology.

Keywords: plant biology, teaching alternative methodology, teaching tools

RESUMO - (O papel da Feira de Ciências como estratégia motivadora para o ensino de Botânica na educação básica). O ensino de Botânica é marcado por inúmeros problemas, como escassez de metodologias que motivem os alunos. Assim, foi proposto aos alunos das disciplinas de Botânica da Licenciatura em Ciências Biológicas da Universidade Estadual do Ceará a elaboração de uma Feira de Ciências, com conteúdo exclusivamente botânico utilizando mapa conceitual e outro material de livre escolha. A feira ocorreu em uma escola da rede pública de Fortaleza, CE, Brasil, com participação de alunos de $9^{\circ}$ ano ao $3^{\circ}$ ano do Ensino Médio. Após sua realização, foi aplicado um questionário aos graduandos de forma a compreender a percepção deles a respeito da atividade. Observou-se que necessitam de uma série de fatores que possibilitem sua execução, dentre eles disponibilidade de recursos e tempo hábil para executá-la. Portanto, conclui-se que essa metodologia desperta o interesse dos alunos pelos assuntos abordados, desde que haja suporte para tal, podendo servir de complemento à metodologia exclusivamente expositiva.

Palavras-chave: biologia vegetal, ferramentas didáticas, metodologia de ensino alternativa

1. Universidade Federal do Ceará, Campus do Pici, Avenida Mister Hull, s/n, 60455-760 Fortaleza, CE, Brasil

2. Universidade Federal do Rio Grande do Norte, Campus Lagoa Nova, Avenida Senador Salgado Filho, 3000, 59078-970 Natal, RN, Brasil

3. Universidade Estadual do Ceará, Centro de Ciências da Saúde, Campus do Itaperi, Avenida Dr. Silas Munguba, 1700, 60740-000 Fortaleza, CE, Brasil

4. Universidade Estadual do Ceará, Faculdade de Educação Ciências e Letras de Iguatu, Campus Multi-institucional Humberto Teixeira, Rua Dário Rabelo, s/n, 63500-000 Iguatu, CE, Brasil

5. Universidade de São Paulo, Instituto de Biociências, Cidade Universitária, Rua do Matão, 277, 05508-090 São Paulo, SP, Brasil

6. Autor para correspondência: bruno.edson@uece.br 


\section{Introdução}

O estudo de Botânica apresenta inúmeros problemas, dentre os quais se destaca a falta de interesse dos estudantes pelos vegetais. A estaticidade das plantas, em contraponto ao dinamismo dos animais, pode ser apontada como um fator que justifica a falta de contato, e um consequente desinteresse significativo, dos seres humanos com os vegetais (Menezes et al. 2008). Em um comportamento denominado por Salatino \& Buckeridge (2016) como negligência Botânica, as plantas sofrem de uma "invisibilidade" para os seres humanos no dia a dia, nos meios de comunicação e na escola, o que dificulta $\mathrm{o}$ interesse dos estudantes. As principais dificuldades na construção do conhecimento de Botânica, assim como das ciências de um modo geral, provêm da falta de aplicação prática do conhecimento, bem como da falta de ferramentas que possibilitem ao aluno despertar interesse no assunto $\mathrm{e}$ ao professor gerar uma força motriz para o surgimento do mesmo (Ceccantini 2006).

Diante dessa problemática, os Parâmetros Curriculares Nacionais (PCN) estabelecem a necessidade de que a instituição escolar garanta um conjunto de práticas didáticas planejadas de forma a contribuir para que os alunos se apropriem dos conteúdos de maneira crítica e construtiva (Brasil 2001a).

A metodologia expositiva é a mais utilizada no ensino de Biologia (Silva et al. 2009). Contudo, é importante notar que as estratégias didáticas que fogem do pragmatismo deste tipo de aula são ferramentas que possibilitam a construção do conhecimento mais atraente, despertam e mantêm o interesse dos alunos, ao mesmo tempo em que proporcionam aos alunos desenvolverem a capacidade de resolver problemas, bem como o desenvolvimento de habilidades para tal, possibilitando assim a compreensão de conceitos básicos (Krasilchik 2005).

Vale ressaltar que essas metodologias alternativas não substituem a prática cotidiana de ensino, uma vez que elas surgem como ações complementares a essa prática. Sendo assim, o uso de metodologias diversas propõe uma "mudança significativa na prática de educadores" que pretendem, de fato, ensinar ciências (Yamazaki \& Yamazaki 2006).

Dessa forma, torna-se necessário que, durante o curso superior, o licenciando tenha conhecimento de estratégias didáticas que desperte o interesse dos alunos. É, portanto, imprescindível uma boa formação dos futuros professores para que estes possam aplicar de forma adequada essas estratégias didáticas (Souza 2007).

Dentre tais estratégias, as feiras de ciências representam uma oportunidade para que os alunos apresentem o conhecimento científico produzido por eles (Brasil 2006a). Segundo Queiroz et al. (2017), as feiras de ciências são práticas de educação não convencionais que objetivam a promoção do desenvolvimento da cultura científica, sendo realizadas tanto em ambientes formais como não formais. Estas são também oportunidades para abrir janelas da curiosidade e interesse do aluno, da criatividade e mobilização do professor, da vida e sentido social da escola (Miranda-Neto et al. s.d.)

A realização de feiras de ciências traz benefícios para alunos e professores e mudanças positivas no trabalho em Ciências, tais como: o crescimento pessoal e a ampliação dos conhecimentos; a ampliação da capacidade comunicativa; mudanças de hábitos e atitudes; o desenvolvimento da criticidade; maior envolvimento e interesse; o exercício da criatividade conduz à apresentação de inovações e a maior politização dos participantes (Mancuso 2000).

Dentre os recursos para se utilizar em uma Feira de Ciências, o mapa conceitual destaca-se por ser uma estrutura esquemática que visa representar uma série de conceitos com base em um conjunto de proposições. Existem vários tipos de mapas conceituais, sendo preferidos por motivos diversos como: facilidade de elaboração, explicitação de processos, hierarquia conceitual que apresenta, entre outros (Tavares 2007).

Em conformidade com esses preceitos, foi realizada uma Feira de Ciências com conteúdo exclusivamente botânico em uma Escola de Ensino Fundamental e Médio na Cidade de Fortaleza, CE, Brasil. Os alunos das disciplinas de Morfologia e Taxonomia de Criptógamas e Morfologia e Anatomia de Espermatófitas do curso de Ciências Biológicas da Universidade Estadual do Ceará (UECE) elaboraram materiais pedagógicos para compor a feira, sendo um deles obrigatoriamente o mapa conceitual. Assim, este trabalho procura contribuir com a formação inicial do futuro docente, ao tentar compreender a visão de alunos da educação superior acerca da utilização da Feira de Ciências como estratégia motivadora para o ensino de Botânica.

\section{Material e métodos}

A pesquisa foi realizada com 35 alunos matriculados nas disciplinas de Morfologia e Taxonomia de Criptógamas e Morfologia e Anatomia de Espermatófitas do curso de licenciatura em Ciências Biológicas da Universidade Estadual do Ceará (UECE).

Inicialmente os licenciandos foram divididos em grupos de dois a quatro alunos, totalizando doze equipes. Por meio de sorteio foi atribuído um tema para cada grupo: Chytridiomycota e Zygomycota, Ascomycota, Basidiomycota, Microalgas, Macroalgas, Hepathophyta e Anthocerophyta, Bryophyta, Lycophyta, Pteridophyta, Características Gerais das Fanerógamas, Morfologia Vegetal, e Anatomia Vegetal.

Cada equipe ficou responsável por produzir dois materiais didáticos em concordância com o tema selecionado para ser aplicado na educação básica. O primeiro foi um mapa conceitual apresentado sob a forma de painel medindo $1,20 \mathrm{x}$ $0,90 \mathrm{~m}$. O segundo foi de livre escolha de cada equipe desde que possibilitasse aos alunos compreender o conhecimento botânico de forma criativa e lúdica; assim, foram produzidos: 
jogos (tabuleiro, cartas ou quiz de perguntas e respostas), modelos tridimensionais, materiais biológicos (herborizados ou in natura), paródias, fotografias e cordéis. As produções de tais recursos não ocorreram durante as aulas da disciplina, contudo, foram supervisionadas pelo monitor e professor da disciplina em momentos extraclasse.

A Feira foi realizada na quadra de esportes de uma escola da rede pública de Fortaleza. Todos os licenciandos chegaram durante o primeiro horário de aula do colégio (07h20min) e organizaram o material produzido em stands, de forma que no segundo horário de aula tudo já estava pronto para a realização da Feira. Em cada um dos stands estava uma equipe diferente de licenciandos para apresentar seu respectivo tema.

Cada equipe apresentou o conteúdo utilizando os recursos desenvolvidos (mapa conceitual e o segundo material didático produzido) para as turmas da escola do $9^{\circ}$ ano do ensino fundamental ao $3^{\circ}$ ano do Ensino Médio, dos turnos da manhã e da tarde, contemplando 16 turmas. A atividade foi planejada para ser desenvolvida com alunos do Ensino Médio. Contudo, as turmas do $9^{\circ}$ ano do Ensino Fundamental II foram adicionadas à atividade, uma vez que tais turmas são trabalhadas em conjunto com o Ensino Médio. A feira iniciou às $08 \mathrm{~h} 10 \mathrm{~min}$, e encerrou às $15 \mathrm{~h}$, totalizando oito horários.

Durante cada horário, permaneceram na quadra apenas duas turmas, totalizando no máximo 60 alunos. Ao chegarem à quadra, foram divididos em grupos e convidados a assistir pelo menos a apresentação de duas equipes com duração média de 8 minutos cada, ficando o resto do tempo livres para visitar os demais stands.

Para avaliar a opinião dos licenciandos sobre o conjunto de atividades realizadas (i.e. a Feira de Ciências e os materiais construídos para compô-la), foi aplicado um questionário contendo 13 perguntas, entre questões objetivas e subjetivas após assinarem um Termo de Consentimento Livre e Esclarecido (TCLE).

Para melhor compreensão dos resultados deste artigo utilizamos o termo licenciando quando nos referimos aos alunos do ensino superior e estudantes para os alunos da educação básica.

Análise das questões objetivas - Para melhor entender a visão dos licenciandos foi utilizada a escala de Stapel (modificada); os respondentes deram notas de 0-10 para as frases selecionadas. Com base nisto, foram tiradas as médias aritméticas e desvio padrão do total de cada resposta. As respostas das questões de múltipla escolha foram divididas e contabilizadas em valores percentuais. Para a questão comparativa entre os interesses iniciais e finais da atividade proposta também foi aplicado o teste $\mathrm{t}$ (Santana \& Ranal 2004). Também foi realizada uma ANOVA, seguido de teste de tukey a $5 \%$ de probabilidade, para compreender os parâmetros de auto avaliação da equipe (organização, estrutura do stand, domínio do assunto, relação entre os membros da equipe, desempenho individual e coletivo e grau de dinamismo com visitantes); bem como uma análise de regressão linear múltipla com os fatores que poderiam afetar este interesse. Para realização destes testes estatísticos utilizou-se o programa BioEstat 5.0 (Ayres et al. 2007).

Análise das questões subjetivas - Para as respostas das questões subjetivas foi aplicada a análise de conteúdo do tipo classificatório de acordo com Bardin (2011). Após a transcrição das mesmas, foi feita uma leitura flutuante de forma a permitir o surgimento de hipóteses sobre os grupos de respostas. Em seguida foi feita uma pesquisa por palavras chave, agregando-as por meio de palavras pertencentes à mesma classe semântica. Por fim, foi traçado o perfil de respostas, agrupando-as em categorias. Dessa forma foi possível avaliar quais foram mais representativas.

Análise do painel com o mapa conceitual - Para definir se o que constava no painel era de fato mapa conceitual ou não foi adotado o que recomenda Tavares (2007). Este trabalho também foi adotado para verificar o tipo e a qualidade do mapa conceitual. Assim, quanto ao tipo os mapas conceituais podem ser: entrada e saída, fluxograma, hierárquico e teia de aranha; quanto à qualidade, podem apresentar conceitos relacionados a mais de um outro conceito e há um grande número de conexões entre os conceitos revelando a familiaridades do autor com o tema, enquanto que uma conexão linear entre os conceitos evidencia poucas possibilidades de entendimento da questão.

Também foi utilizada a classificação de Anastasiou \& Alves (2004) para a avaliação do conteúdo e organização das informações. Nela, levamos em consideração a riqueza de conceitos básicos expostos no mapa, a representatividade desses dentro do contexto do tema da equipe e a organização das informações.

\section{Resultados e discussão}

Quando os alunos licenciandos foram indagados a acerca da importância do ensino de Botânica, as respostas foram variadas. Observaram-se três categorias de respostas, descritos abaixo em ordem decrescente de representatividade:

1. Botânica é importante para a compreensão da vida e diversidade de espécies (59\%);

2. Botânica é uma disciplina ministrada nas escolas, portanto, é importante o seu estudo para que o ato de lecionar seus conteúdos seja melhor executada $(24 \%)$;

3. Botânica faz parte do cotidiano e é interdisciplinar $(17 \%)$.

Uma vez que $59 \%$ das respostas dos discentes estiveram na categoria 1 fica evidente a visão que para o entendimento da vida como um todo, isto é, todos os seres vivos e suas inter-relações, é necessário que se estude a Botânica. Esta área se preocupa em estudar, entre outros aspectos, a diversidade, morfologia, ecologia, fisiologia e reprodução 
as plantas e também, em um sentido mais amplo, de fungos e algas. Tais organismos, além de compreenderem uma porção considerável da vida na terra, são fundamentais para à manutenção dos ecossistemas.

Para 24\% dos licenciandos, o estudo de Botânica é necessário, pois é uma disciplina ministrada nas escolas e para $17 \%$ a Botânica é importante, pois está no nosso cotidiano e é interdisciplinar. Para que a interdisciplinaridade ocorra de uma forma mais fácil é necessário um trabalho pedagógico cooperativo entre os professores (Hartmann \& Zimmermann 2009), e o despertar dessa concepção durante a graduação pode ser o ponto chave para que isso ocorra.

Diante desses resultados, podemos inferir que enxergar a Botânica apenas como uma disciplina a ser lecionada pode ser efeito da própria formação básica problemática dos licenciandos. Isso pode ocorrer pois os professores de ensino básico que lecionaram Botânica para os atuais licenciandos não nutriam entusiasmo pela área, não conseguindo assim motivar seus alunos. Como consequência, os licenciandos possuem a mesma falta de sentimento, que possivelmente será passada para seus alunos, formando assim um círculo vicioso prejudicial ao ensino de Botânica (Salatino \& Buckeridge 2016).

Tais opiniões mostram que, embora a Botânica esteja presente no dia a dia, não são todos os futuros profissionais que enxergam essa realidade. Tratando-a apenas como uma "obrigação", entra em confronto com a ideia de que uma aplicação prática do assunto seja necessária para o bom entendimento dessa ciência (Ceccantini 2006). Logo, podemos inferir que ver a Botânica apenas como uma obrigação é sinal de que a cegueira Botânica está presente no contexto dos alunos da graduação do curso de Ciências Biológicas que forma futuros professores. Salatino \& Buckeridge (2016), afirmam que a cegueira Botânica pode acarretar uma série de prejuízos a sociedade, como a falta de sentimento de preservação de florestas e o não reconhecimento de atividades econômicas como a agricultura. Nesse viés, é preocupante observar que os futuros docentes, que serão importantes personagens na construção de sentido dos estudantes do ensino básico, não reconhecem a importância dos organismos estudados na Botânica dentro do complexo contexto dos sistemas biológicos. Assim, a pavimentação de uma consciência ambiental fica prejudicada, visto que entender a importância de todos os seres vivos dentro dos ecossistemas é fundamental para a preservação do meio ambiente.

Quando foi pedido que os licenciandos dessem a sua opinião acerca da importância da Feira de Ciências com conteúdo exclusivamente botânico para a sua formação, foram encontradas duas categorias de resposta:

1. Contato com os alunos da educação básica e ambiente escolar;

2. Desenvolver e aplicar estratégias de ensino.
Para $85 \%$ dos entrevistados a Feira de Ciências é uma experiência para uma futura prática docente uma vez que ocorreu diretamente no ambiente escolar, enquanto $15 \%$ dos alunos a participação no evento possui poder de qualificar a formação do licenciando mostrando diferentes estratégias de ensino. Tais resultados corroboram com as preposições dos PCN (Brasil 2001a), que uma formação consistente, possibilita ao professor a elaboração de estratégias que proporcionem um aprendizado crítico e construtivo. Fica evidente a necessária mudança de pensamento no modo de ensinar os futuros professores, sendo de extrema importância a experiência com metodologias alternativas, assim como está disposto no Parecer CNE/CP 28/2001 (Brasil 2001b) e na Resolução CNE/CP 02/2002 (Brasil 2002).

Quando indagados sobre a experiência de lidar com outros recursos didáticos que não eram acostumados a utilizar no curso de Ciências Biológicas, neste caso o mapa conceitual e a produção de um segundo material didático (jogos, modelos tridimensionais, materiais biológicos, paródias, fotografias ou cordéis), foi observada uma divisão de respostas em duas categorias:

1. Foi uma experiência importante, pois esses recursos didáticos são valiosas ferramentas de ensinoaprendizado;

2. O ensino com recursos não convencionais é difícil e exige preparo.

Para 57\% dos alunos, é importante ter experiência com diferentes recursos didáticos. Essas respostas mostram a preocupação dos licenciandos em conhecer metodologias que permitam planejar e executar atividades interessantes para os alunos. Silva \& Moraes (2011) destacam a importância de selecionar estratégias que permitam tornar o processo de aprendizagem prazeroso. Nesse contexto, a utilização de metodologias alternativas, como jogos e brincadeiras, está prevista nos Parâmetros Curriculares Nacionais (PCNs), pois permitem que os alunos desenvolvam diversas aptidões durante o processo de aprendizagem, como comunicação, liderança, inter-relações de trabalho e cooperação (Brasil 2001a).

De acordo com 29\% dos alunos existem diversas dificuldades de aplicar esses recursos, como a falta de estrutura física das escolas e verba, a utilização do tempo e a falta de experiência em usar esses recursos. A falta de políticas públicas influencia no desempenho docente, uma vez que as precárias condições de trabalho (e.g. falta de ferramentas, tempo e espaço para a execução de atividades) desmotivam e desvalorizam o profissional docente (Patti et al. 2017). Assim, mesmo os licenciandos não exercendo a profissão, a falta de políticas públicas, ou a não execução delas, ficou bastante evidente para eles.

Observamos ainda que 14\% dos alunos não responderam ao questionamento. Segundo Maturana (2002), o processo educacional tem efeitos de longa duração, e esses não são modificados facilmente. Como consequência, podemos 
inferir que a falta de vontade de responder ao questionamento pode estar associado a fatores construídos durante a formação do licenciando. Esses podem estar relacionados com a recursividade da falta de políticas públicas que fomentem a utilização de estratégias alternativas (Patti et al. 2017), bem como com a utilização predominante da metodologia tradicional expositiva no ensino de Biologia (Silva et al. 2009). Como consequência, os licenciandos não desenvolveram ao longo de sua formação afetividade com as estratégias alternativas, podendo negligenciar a participação na pesquisa (Maturana 2002).

De acordo com as respostas obtidas fica claro que, embora haja intenção de usar recursos que fogem do modelo tradicional de aula, existem fatores que podem dificultar sua prática. No entanto, apesar de haver dificuldades relacionadas ao tempo disponível para a execução destes recursos, é importante colocar tais práticas em ação, tornando a construção de conhecimento mais interessante para o aluno, fazendo com que a aprendizagem seja mais significativa (Pliessnig \& Kovaliczn 2008). Vale ressaltar que tais estratégias são importantes ferramentas para complementar o ensino tradicional expositivo (Yamazaki \& Yamazaki 2006), modificando o panorama do ensino de Botânica, pois esse se caracteriza por ser muito teórico e desestimulante para os alunos (Kinoshita et al.2006).

Os resultados obtidos possibilitaram visualizar algumas vantagens e desvantagens da utilização de recursos didáticos não convencionais como forma de auxiliar na disseminação crítica do conhecimento botânico.

Quando perguntados sobre o critério utilizado para a escolha do segundo material didático apresentado (figura $1 \mathrm{a}$ ), além do mapa conceitual solicitado, notou-se que a maioria dos grupos (29\%) procurou uma opção que proporcionasse mais dinamismo, de forma a atrair o interesse dos alunos da escola. O método utilizado também foi selecionado com base na melhor exploração dos recursos visuais (22\%). Tais afirmações corroboram com Ceccantini (2006), este afirma que o recurso deve atrair a atenção do aluno e permitir que o professor consiga uma força propulsora para que esse interesse surja, construindo materiais lúdicos mesmo na escassez de recursos para tal por meio da sua criatividade. Portanto, o dinamismo entre o apresentador e o visitante, bem como a exploração dos recursos visuais são de extrema importância para que isso ocorra.

Quando perguntados sobre como classificariam o Mapa Conceitual (figura $1 \mathrm{~b}$ ), a maioria dos alunos respondeu que ele é um excelente guia de apresentação, assim como é um instrumento de uso prático ( $34,5 \%$ cada). Tavares (2007) ressalta que ele pode ser amplamente utilizado, devido sua praticidade e que atinge o objetivo de nortear a apresentação, fazendo dele ferramenta interessante para prender a atenção dos alunos.

De acordo com a visão dos licenciandos, os estudantes foram motivados para as apresentações majoritariamente pelos recursos visuais ( $37 \%$ das respostas), ou por curiosidade
(33\%), conforme mostra a figura $1 \mathrm{c}$, e não por imposição da escola (18\%). É possível inferir que a ferramenta didática, diferente da aula convencional, alcançou seu objetivo ao motivar os alunos para a aprendizagem do conteúdo.

Durante a realização das atividades foi possível notar um aumento no interesse dos licenciandos em relação ao projeto, fator essencial para a construção de conhecimento acontecer de forma prazerosa (Pliessnig \& Kovaliczn 2008). Após a explicação da atividade foi solicitado que os discentes avaliassem seu interesse no projeto em uma escala de $0-10$. O resultado do interesse inicial médio foi estimado em 6,8 . Porém, após a execução da feira, a avaliação foi novamente aplicada e a média aumentou para 8,0 . As médias são estatisticamente diferentes pelo teste $\mathrm{t}$ $(\mathrm{t}=-2,2709 / \mathrm{GL}=68 / \mathrm{p}=0,0263)$. O aumento no interesse dos licenciandos é um dos benefícios concedidos pela realização das feiras (Nascimento 2012). Através da análise de regressão múltipla nota-se que a mudança no interesse dos alunos antes e depois da atividade $(\mathrm{F}=4,4095 ; \mathrm{GL}=3$; $\mathrm{p}=0,011 ; \mathrm{R}^{2}$ ajustado $\left.=0,2366\right)$ deveu-se principalmente a receptividade dos visitantes $(\mathrm{p}=0,0066)$ e não teve relação com a disponibilidade de recursos e metodologias $(p=0,7035)$ e de revisão de literatura $(p=0,2611)$.

Esses dados mostram que o fortalecimento das relações afetivas entre professor e aluno (neste caso licenciando e estudante) contribui para uma maior fluência do processo de ensino-aprendizagem (Sarnoski 2014). Patti et al. (2017) afirmam que a interação, comportamento e aprendizagem dos alunos, apresentam-se como principais aspectos de motivação e realização docente. Por outro lado, demostra uma defasagem de recursos e ações que estimulem a utilização de uma maior variedade de estratégias educativas, uma vez que o ensino de Botânica ainda se encontra muito atrelado ao método tradicional expositivo (Silva et al. 2009), sendo assim necessárias melhorias nas suas técnicas de ensino (Rawitscher 1937, Barradas \& Nogueira 2000, Kinoshita et al. 2006, Towata et al. 2010).

Quando os licenciandos foram questionados ao final da Feira sobre as abordagens de quais equipes foram mais interessantes (figura $1 \mathrm{e}$ ), notou-se que "Macroalgas" (17 citações) e "Características Gerais das Fanerógamas" (12 citações) foram as apresentações mais efetivas nesse aspecto, correspondendo a $23 \%$ e $14,9 \%$, respectivamente.

O grupo de "Macroalgas" utilizou como recurso didático o quiz de perguntas e respostas, interagindo bem com os alunos visitantes da feira. Isso ressalta a importância do dinamismo para o ensino de Botânica, tal fato deve ser levado em conta para que o ensino dessa ciência não se dê de forma monótona e dificulte a construção do conhecimento (Silva et al. 2016). Já o resultado obtido pelo grupo "Características Gerais das Fanerógamas", pode estar relacionado à dois fatores: 1) o fato desse grupo em especial estar mais presente no dia a dia do ser humano em comparação a outros grupos, como Lycophyta; 2) o recurso utilizado por essa equipe ter sido cordel. 

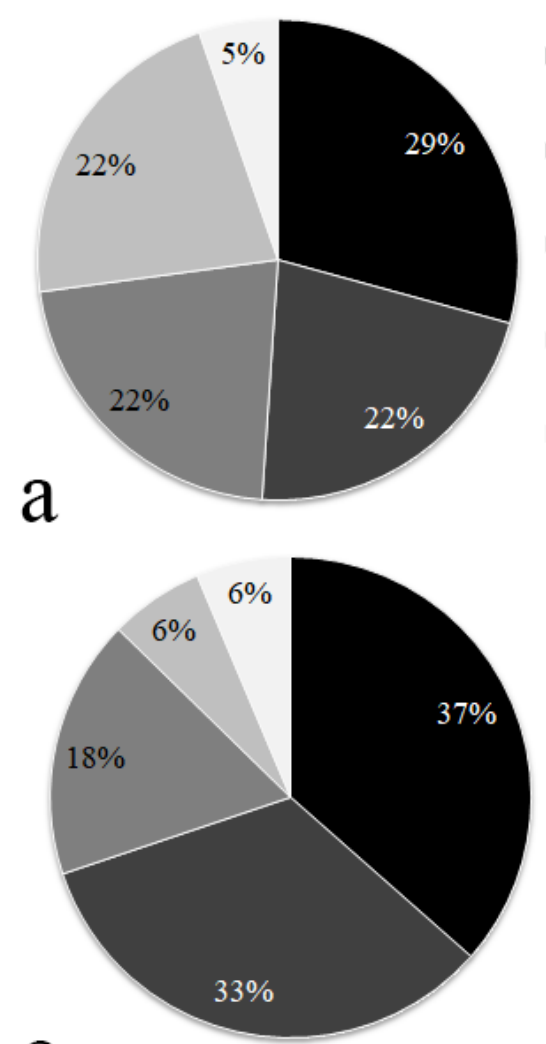

C

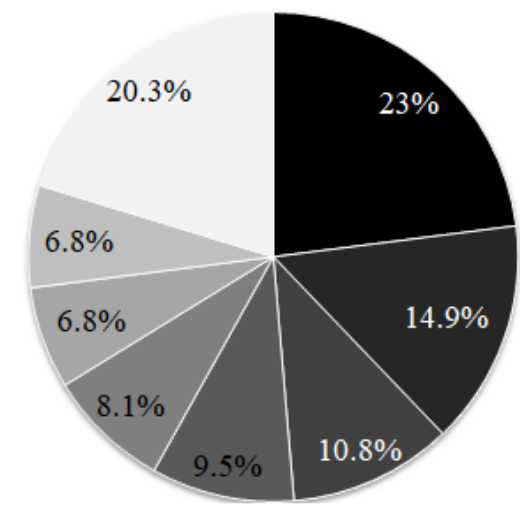

- Dinamismo com os visitantes

- Compatibilidade com conteúdo

- Praticidade de execução

- Exploração de recursos visuais

Outros

- Atraídos pelos recursos expostos no stand

- Curiosidade

- Imposição do colégio

Interesse pelo conteudo

- Macroalgas

- Carac. gerais das fanerógamas - Briophytas

- Hepatophyta e Anthocerophyta - Ascomycota

- Microalgas

Morfologia vegetal

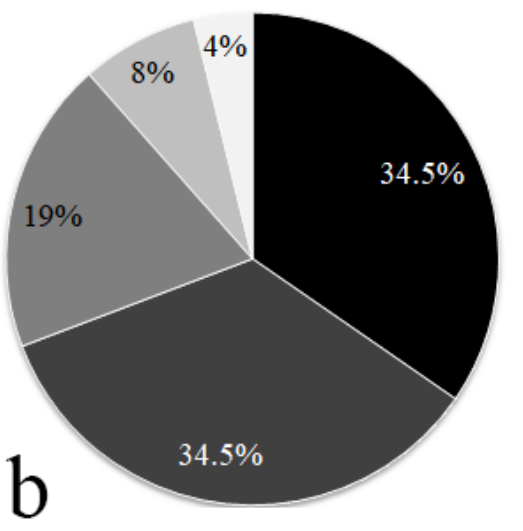

- Prático

- Excelente guia de apresentação

- Corresponde as necessidades

n Pouco educativo

Outros

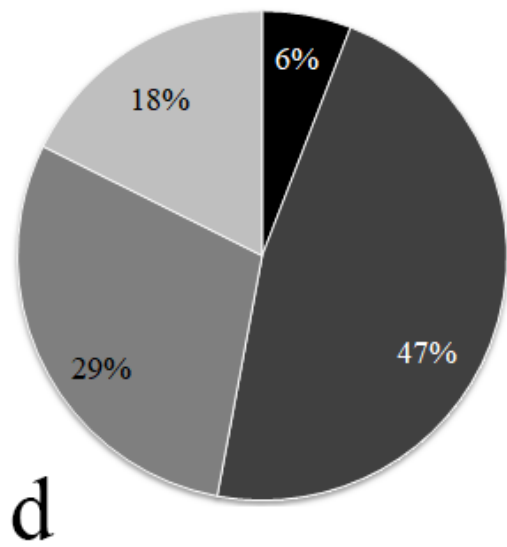

- Fácil

- Intermediário

Difícil

Muito difícil

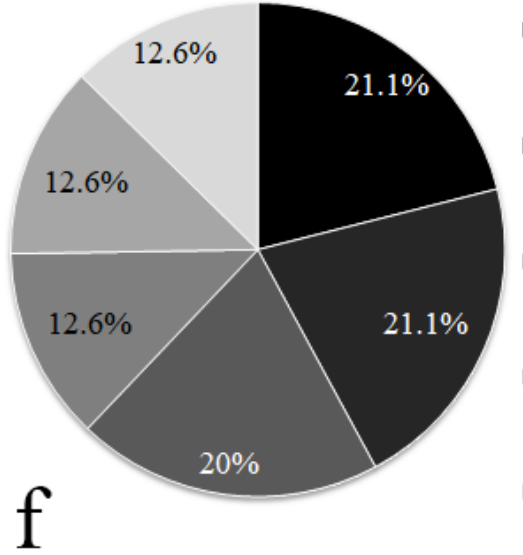

- Aparentemente dispersos

- Atentos à apresentação

- Questionadores

- Interessados em participar das dinâmicas

- Respondiam aos questionamentos

Figura 1. Respostas dos alunos graduandos para questões objetivas em porcentagem. a. Critério para a seleção da metodologia utilizada. b. Classificação do mapa conceitual. c. Percepção da motivação dos alunos. d. Nível de dificuldade na execução do evento. e. Receptividade ao recurso didático utilizado nas apresentações das equipes. f. Percepção dos apresentadores acerca da reação dos visitantes.

Figure 1. Responses of undergraduate students to objective questions in percentage. a. Discretion for the selection of the methodology used. b. Rating of conceptual map. c. Perception of student motivation. d. Difficulty level in the execution of the event. e. Receptivity to teaching resource used in the presentations of the teams. f. Perception of the presenters about the reaction of visitors.

Vale ressaltar ainda que foi observada bastante motivação tanto dessas equipes quanto dos visitantes durante a atividade, o que para Freire (1987) é fator importante para a construção do conhecimento. O jogo didático, como o quiz de perguntas e respostas, utilizado pela equipe "Macroalgas" são uma estratégia didática que desperta interesse nos alunos (Towata et al.2010) e faz com que o processo de ensino-aprendizagem aconteça de maneira leve e natural (Edson-Chaves et al. 2015). Essa ferramenta possibilita aliar aspectos lúdicos ao cognitivo, sendo de grande importância para a aprendizagem de conceitos complexos e abstratos, o que favorece a motivação, a argumentação, o raciocínio e a interação, tanto entre os alunos, como entre alunos e professores (Campos et al. 2003). 
O cordel é uma expressão artística com marcas profundamente presentes na cultura nordestina, que surgiu inicialmente na forma oral, influenciado pelos romances portugueses em versos, e posteriormente passou para a forma escrita (Alves 2008). Assim, a representatividade do grupo "Características Gerais das Fanerógamas" pode estar relacionada com a ferramenta escolhida (cordel), uma vez que, quando dentro do contexto em que o aluno se insere, a ferramenta pode aumentar a motivação pelo conhecimento científico (Delizoicov et al. 2002).

Por outro lado, a abordagem da equipe de "Lycophyta" foi a que menos chamou atenção. É possível que tal fato possa estar relacionado a dois fatores: 1) o fato desse grupo ser ainda menos comum no dia a dia dos estudantes em comparação a outros grupos (e.g. Fanerógamas, Macroalgas), intensificando ainda mais a sensação de dessemelhança com o grupo botânico em questão (Salatino \& Buckeridge, 2016); 2) o recurso utilizado por essa equipe ter sido a fotografia de um exemplar de Lycophyta, que não permite a devida interação entre visitante e apresentador.

As reações dos estudantes que foram percebidas pelos apresentadores licenciandos (figura $1 \mathrm{f}$ ) foram bem variadas, entretanto, vale ressaltar que em geral elas foram bastante positivas, como: visitantes atentos à apresentação (20 citações), questionando (19 citações), interessados em participar (12 citações) e respondendo aos questionamentos (12 citações). Este dado reforça que o dinamismo entre visitantes e apresentadores é um ganho importante da utilização de metodologias lúdicas e criativas na construção de conhecimento (Ceccantini 2006). Contudo, as citações de visitantes aparentemente dispersos (32 citações) revelam que nem todas as equipes conseguiram utilizar ferramentas que fossem exitosas em realizar a associação entre teoria e prática, refletindo consequentemente na falta de interesse nessas apresentações (Orvatti \& Bueno 2012).

Quando solicitado que fosse feita uma autoavaliação do seu grupo, os alunos tiveram uma percepção de que, embora com recursos insuficientes, a sua equipe conseguiu realizar um bom trabalho. A média mais baixa foi para a estrutura do stand (Média $=8,06 \pm 1,43$ ) e as mais altas foram para relação entre os membros da equipe (Média $=9,06 \pm$ 1,49) e o bom desempenho tanto individual quanto coletivo (Média $=9,09 \pm 1,17$ ). Tais relações foram estatisticamente diferentes entre si. Os dados de organização da equipe (Média $=8,29 \pm 1,54$ ), domínio do conteúdo (Média $=$ $8,94 \pm 1,06)$ e dinamismo entre visitantes e apresentadores (Média $=8,91 \pm 1,27$ ), apresentou dados estatisticamente semelhante aos demais.

Assim sendo, a importância da formação do professor para que este seja força motriz do surgimento de interesse dos alunos, bem como o dinamismo entre apresentadores e visitantes como um ganho importante na utilização de estratégias alternativas de ensino (Ceccantini 2006) voltam a ficar evidentes.
Em relação à complexidade da realização de um evento como esse (figura $1 \mathrm{~d}$ ), percebeu-se que os alunos tiveram dificuldade, visto que nenhum indicou o evento como "muito fácil" e que apenas $6 \%$ classificou como de "fácil" execução. Por outro lado, $29 \%$ classificou a atividade como "difícil" e $18 \%$ como "muito difícil". Estes dados assemelham-se às dificuldades relacionadas ao tempo mencionadas por Pliessnig \& Kovaliczn (2008). Tais dificuldades dizem respeito à necessidade de sempre estar atualizado tanto da teoria quanto das metodologias para que a prática pedagógica seja realizada de forma satisfatória. Dessa forma, as metodologias alternativas se tornam custosas, demandando tempo para planejamento e execução. Vale destacar que a realização de uma "Feira de Ciências" deve ser a culminação de um trabalho contínuo, e não uma realização extemporânea (Gonçalves 2008). Dessa forma, pode-se revelar uma escassez de tempo para planejamento e execução da feira, o que pode ter tornado a atividade mais custosa do que poderia ser se o tempo fosse maior.

No que se refere aos aspectos positivos e negativos da realização da Feira de Ciências, 53\% das respostas a respeito dos aspectos positivos, bem como $58 \%$ das respostas sobre os aspectos negativos, foram deixadas em branco. Quanto aos aspectos positivos, foram encontradas cinco categorias de resposta, apresentadas em ordem decrescente de citações:

1. Auxílio na aprendizagem do assunto apresentado $(30 \%)$;

2. Oportunidade de praticar a docência (28\%);

3. A experiência de lidar com alunos e ambiente escolar $(23 \%)$

4. Motivação para a construção de conhecimento de Botânica (13\%);

5. Interação com futuros colegas docentes (6\%).

Quanto aos aspectos negativos, também foram encontradas cinco categorias de respostas, apresentadas em ordem decrescente de citações:

1. Tempo disponível para a execução da atividade $(26 \%)$;

2. Cansaço pela realização da atividade $(26 \%)$;

3. Organização da feira $(23 \%)$;

4. Dificuldade em transmitir o conteúdo (16\%);

5. Falta de recursos para a realização da atividade $(9 \%)$.

Assim, observa-se que enquanto ocorrem a inserção profissional e a aquisição de conhecimento destacados nos aspectos positivos deste trabalho, o tempo disponível para pôr em prática estratégias alternativas de ensino é um fator limitante destas atividades. Esses dados estão de acordo com o que cita Pliessnig \& Kovaliczn (2008) e Barcelos et al. (2010), que discutem a falta de tempo para que o professor 
possa estar atualizado quanto às metodologias e para poder coloca-las em prática. Vale ressaltar que pelo fato de o ensino de Botânica ser feito principalmente da forma tradicional expositiva (Silva et al. 2009) podem surgir dificuldades de como ensinar com formas alternativas, podendo refletir em falta de organização e cansaço. Dessa forma, é evidente que, por mais que se trate de uma proposta que necessita de um planejamento e tempo para execução, a Feira de Ciências é uma metodologia que permite uma atenuação da cegueira Botânica, fazendo com que os estudantes construam um sentido para o conhecimento (Barcelos et al. 2010) de forma lúdica e prazerosa.

Avaliação dos mapas conceituais - A equipe "Anatomia Vegetal" não confeccionou o painel com material durável, o que ocasionou sua danificação e consequente inviabilidade de avaliação. As equipes "Microalgas", "Macroalgas" e "Hepatophyta e Anthocerophyta" não construíram mapas conceituais, se restringindo a montar um painel com informações acerca dos seus temas (figura 2).

Das equipes que construíram mapas conceituais, as equipes "Ascomycota", "Basidiomycota" e "Morfologia Vegetal" construíram mapas do tipo fluxograma, enquanto a equipe "Briophyta" construiu um mapa do tipo teia (figura 3). Já as equipes "Chytridiomycota e Zygomycota" e "Características Gerais das Fanerógamas" construíram mapas do tipo entrada e saída, e as equipes "Lycophyta" e "Pteridophyta" por sua vez optaram por mapas do tipo hierárquico (figura 4).
Não existem mapas conceituais certos ou errados, existem mapas com demonstrações de grande conhecimento de relações entre os conceitos expostos (Tavares 2007). Os únicos mapas que não apresentaram essas características foram os das equipes "Basidiomycota" e "Pteridophyta", uma vez que ambas apresentaram uma conexão linear dos conceitos.

Outro aspecto importante na avaliação do mapa conceitual diz respeito à representatividade do conteúdo trabalhado (Anastasiou \& Alves 2004). Nesse caso, somente as equipes "Ascomycota", "Basidiomycota" e "Pteridophyta" não conseguiram apresentar no mapa uma porção representativa do conteúdo para o nível dos alunos. Outras equipes como "Morfologia Vegetal", "Características Gerais das Fanerógamas" e "Basidiomycota" conseguiram apresentar boa parte do conteúdo acerca dos seus temas, contudo a representação ocorreu de forma desorganizada, dificultando a visualização e consequente entendimento dos conceitos presentes no mapa conceitual. A organização das informações e a clareza de conceitos são dois fatores que possuem uma relação próxima, os quais também são critérios para a avaliação de um mapa conceitual (Anastasiou \& Alves 2004). Desta forma, os únicos mapas conceituais dentro de ambas as recomendações de avaliação foram os mapas das equipes "Bryophyta" e "Lycophyta", enquanto os mapas das equipes "Pteridophyta" e "Basidiomycota" não corresponderam bem aos critérios avaliados (qualidade, conteúdo e organização).
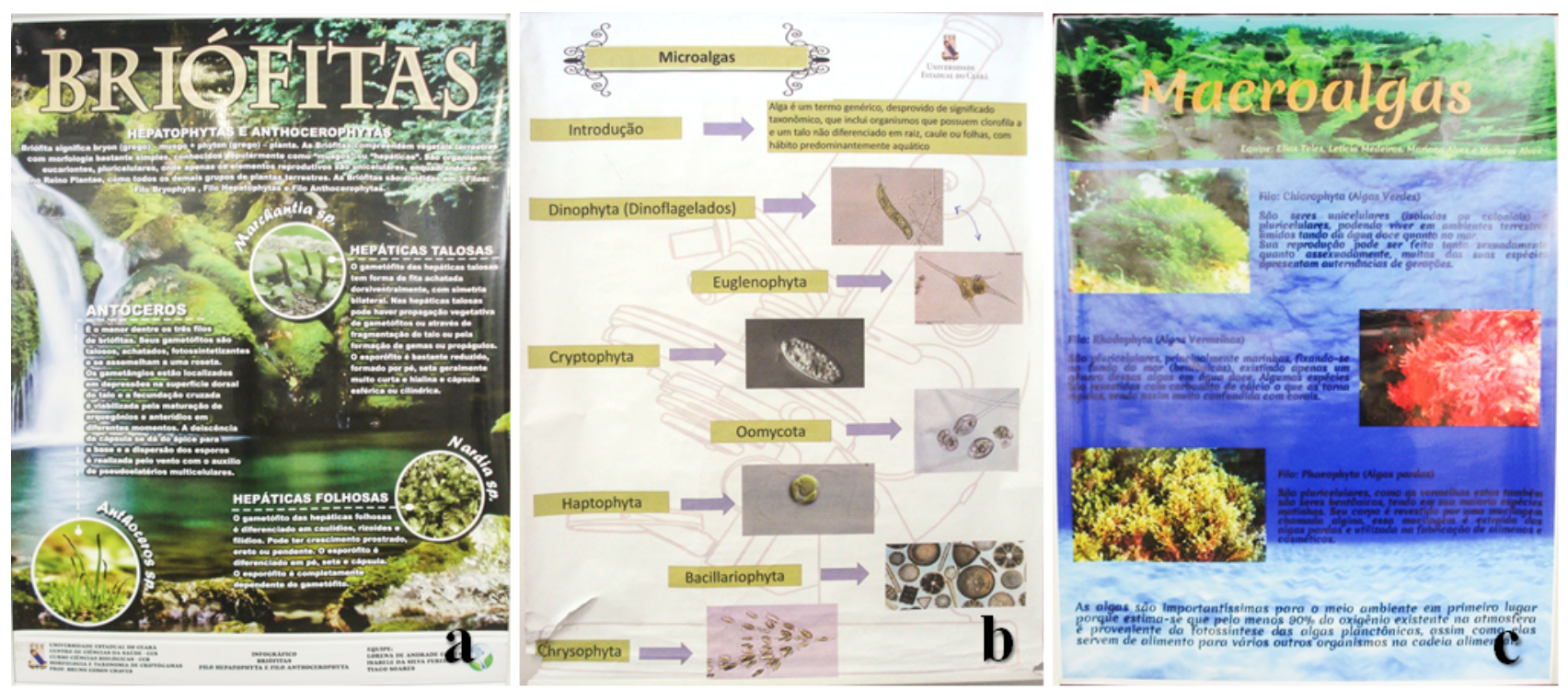

Figura 2. Painéis desprovidos dos mapas conceituais. a. Hepatophyta e Anthocerophyta. b. Microalgas. c. Macroalgas.

Figure 2. Panels without of conceptual maps. a. Hepatophyta and Anthocerophyta. b. Microalgae. c. Macroalgae. 

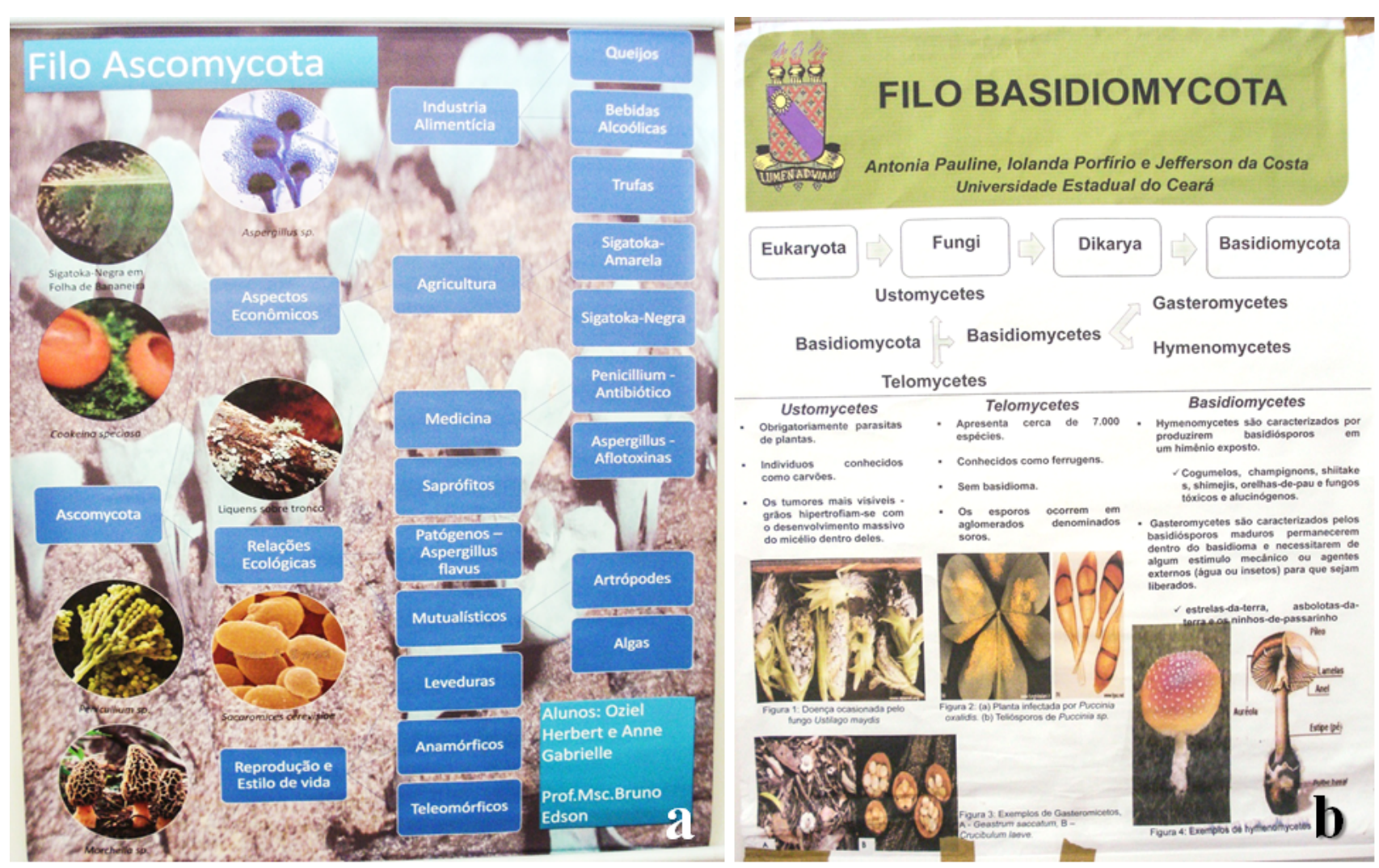

\begin{tabular}{|c|c|c|c|}
\hline Eukaryota & Fungi & Dikarya & Basidiomycota \\
\hline \multicolumn{4}{|c|}{ Ustomycetes } \\
\hline
\end{tabular}
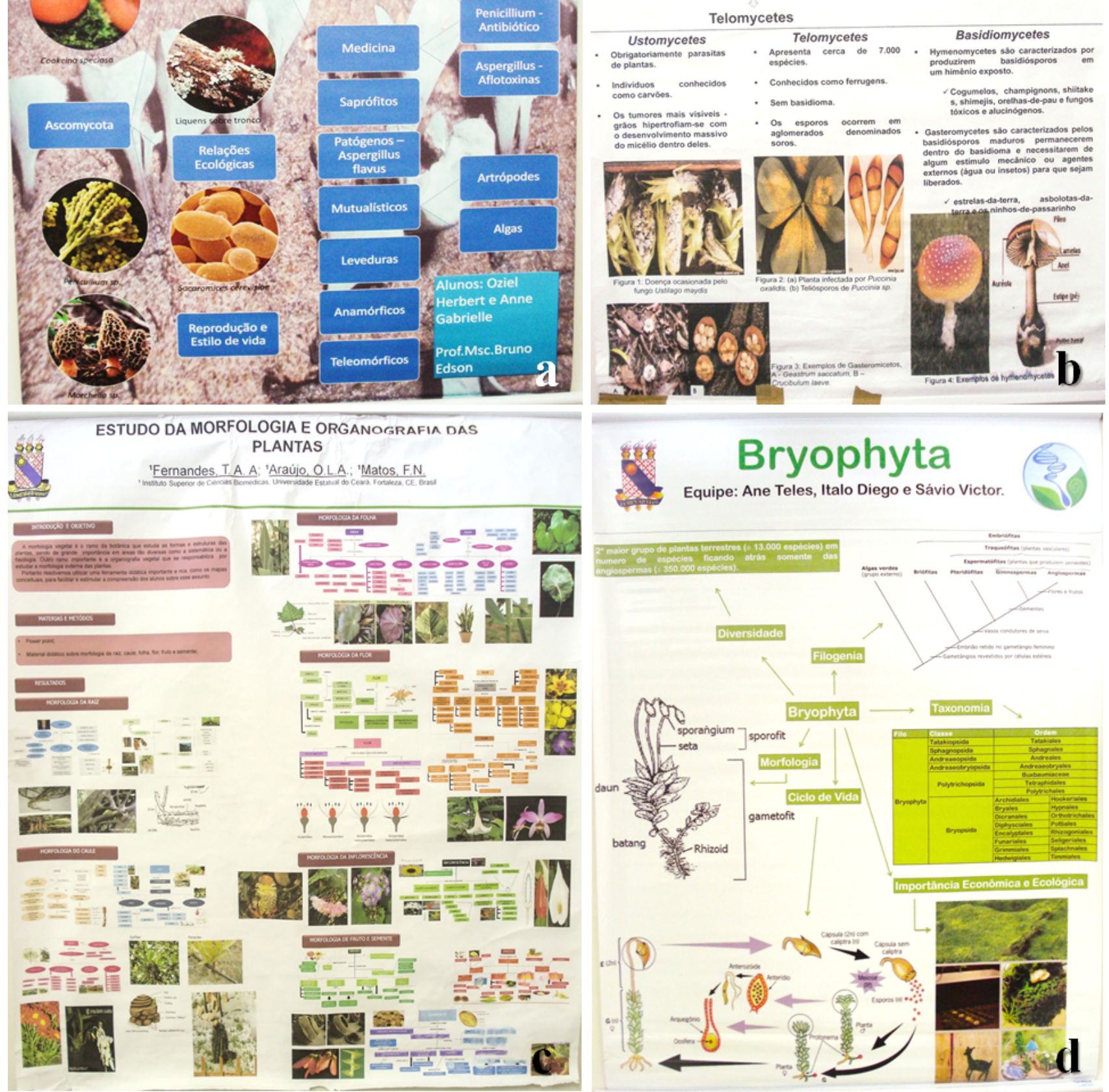

Figura 3. Painéis com mapas conceituais do tipo fluxograma (a, b e c) e teia (d). a. Ascomycota. b. Basidiomycota. c. Morfologia Vegetal. d. Bryophyta.

Figure 3. Panels with conceptual maps flowchart type ( $a, b$ and c) and web (d). a. Ascomycota. b. Basidiomycota. c. Plant Morphology. d. Bryophyta. 

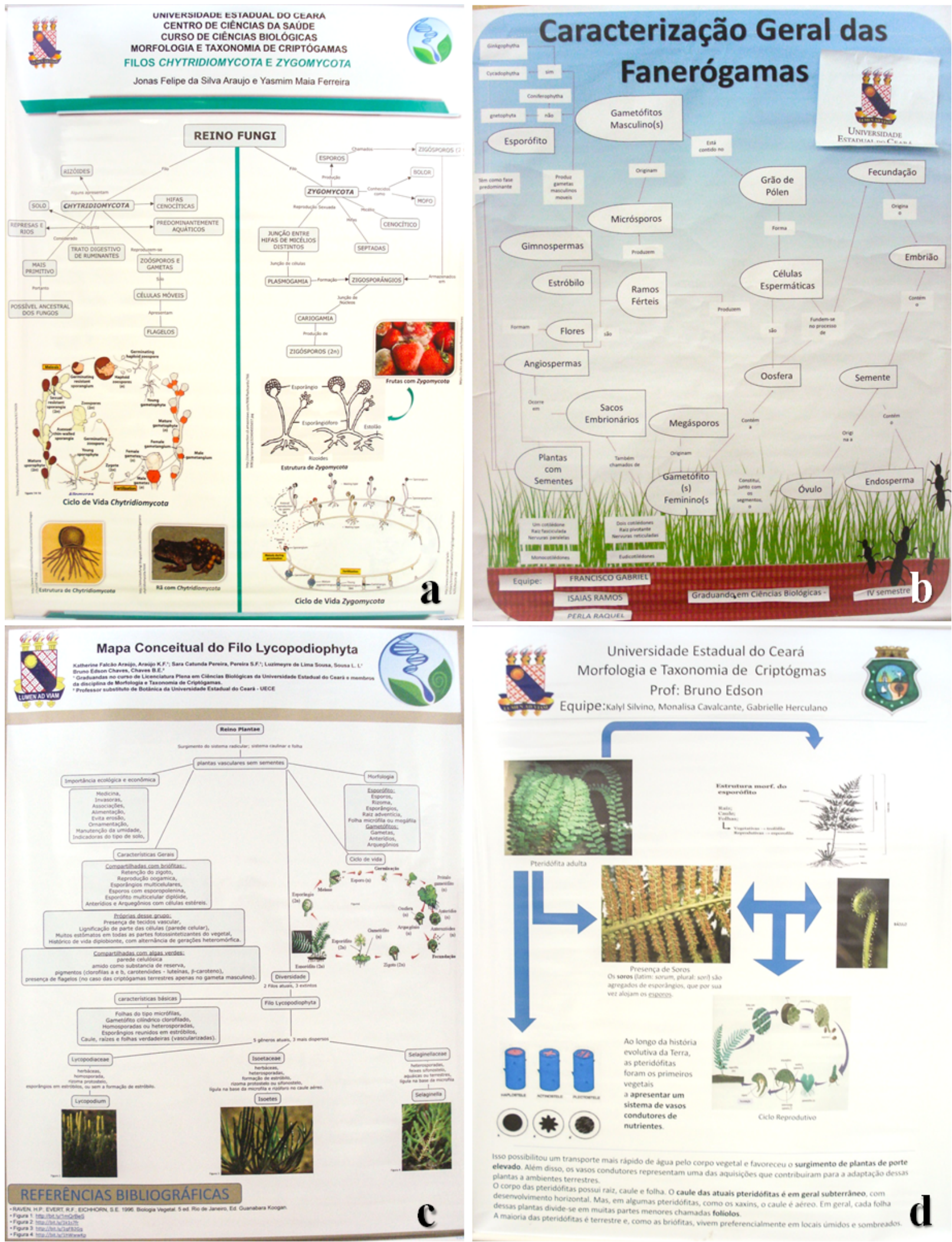

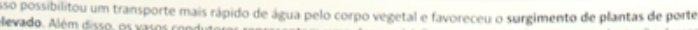

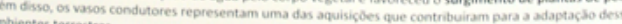

(a)

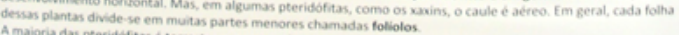

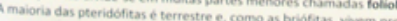

Figura 4. Painéis com mapas conceituais do tipo entrada e saída (a e b) e hierárquico (c e d). a. Chytridiomycota e Zygomycota. b. Características Gerais das Fanerógamas. c. Pteridophyta. d. Lycophyta.

Figure 4. Panels with conceptual maps of type input and output ( $a$ and b) and hierarchical (c and d). a. Chytridiomycota and Zygomycota. b. General Characteristics of Phanerogams. c. Pteridophyta. d. Lycophyta. 


\section{Conclusões}

O ensino por meio de metodologias não convencionais, neste caso uma Feira de Ciências, proporciona aos alunos o surgimento de uma curiosidade sobre o tema. Se bem trabalhada, essa curiosidade pode se transformar em um interesse contínuo, contribuindo para um aumento do conhecimento científico dos licenciandos.

É notável também que para que essas técnicas sejam executadas com êxito é necessária uma série de fatores, como trabalho árduo, interdisciplinaridade com outras áreas do conhecimento e disponibilidade de recursos e de aporte teórico.

Alguns trabalhos obtiveram um rendimento superior a outros em alguns aspectos. As equipes de "Características Gerais das Fanerógamas" e "Macroalgas" obtiveram bastante sucesso no que diz respeito a interagir com os alunos da escola, bem como motivá-los para o aprendizado em Botânica. Essas equipes tiveram os recursos didáticos mais bem recebidos, cordel e jogos didáticos, respectivamente, confirmando a premissa de que estratégias inseridas na realidade cultural dos alunos (cordel) e atividades lúdicas e interativas (jogos didáticos) são ferramentas que proporcionam um interesse maior dos estudantes pela construção de conhecimento.

Quanto ao mapa conceitual, embora a maioria das equipes tenha construído mapas ruins, este foi avaliado como uma importante ferramenta didática para o ensino de Botânica. Esses resultados também confirmam que é necessário que exista uma formação dos futuros professores para aplicarem ferramentas didáticas que fogem do pragmatismo da aula expositiva. Desta forma, as ferramentas construídas por eles quando estiverem na sua atividade docente poderão ser de melhor qualidade.

Portanto, a Feira de Ciências é uma estratégia didática viável para ser aplicada como motivação para estudantes, desde que haja suporte para sua realização. Essa atividade pode ser utilizada como complemento ao ensino tradicional expositivo de Botânica, aumentando o interesse dos alunos pela área e possibilitando uma construção mais sólida do conhecimento.

\section{Literatura citada}

Alves, R.M. 2008. Literatura de cordel: por que e para que trabalhar em sala de aula. Revista Forúm Identidades 4(4): 103-109.

Anastasiou, L. das G.C. \& Alves, L.P. 2004. Processos de ensinagem na Universidade: pressupostos para estratégias de trabalho em aula. 3. ed. Univille, Joinville.

Ayres, M., Ayres Jr, M., Ayres, D.L. \& Santos, A.A.S. 2007. BioEstat 5.0: aplicações estatísticas nas áreas das ciências biológicas e médicas. 5. ed. Instituto de Desenvolvimento Sustentável Mamirauá, Belém.
Barcelos, N.N.S., Jacobucci, G.B. \& Jacobucci, D.F.C. 2010. Quando o cotidiano pede espaço na escola, o projeto da Feira de Ciências "Vida em sociedade" se concretiza. Ciência e Educação 16(1): 215:233.

Bardin, L. 2011. Análise de conteúdo. Edição revista e ampliada. Edições 70, São Paulo.

Barradas, M.M. \& Nogueira, E. 2000. Trajetória da Sociedade Brasileira de Botânica. Sociedade Brasileira de Botânica, Brasília.

Brasil. 2001a. Secretaria da Educação Fundamental. Parâmetros Curriculares Nacionais: Ciências Naturais. 3. ed. MEC/SEF, Brasília.

Brasil. 2001b. Ministério da Educação. Parecer CNE/CP 28/2001, 16 p. Disponível em http://portal.mec.gov.br/ cne/arquivos/pdf/028.pdf (acesso em 20-I-2015).

Brasil. 2002. Ministério da Educação. Resolução CNE/CP 02/2002, 1p. Disponível em

http://portal.mec.gov.br/cne/arquivos/pdf/CP022002.pdf (acesso em 20-I-2015).

Brasil. 2006. Secretaria de Educação Básica. Programa Nacional de Apoio às Feiras de Ciências da Educação Básica. Brasília: MEC/SEB.

Campos, L.M.L., Bortoloto, T.M. \& Felicio, A.K.C. 2003. A produção de jogos didáticos para o ensino de Ciências e Biologia: uma proposta para favorecer a aprendizagem. Caderno dos Núcleos de Ensino 47: 47-60.

Ceccantini, G. 2006. Os tecidos vegetais têm três dimensões. Revista Brasileira de Botânica 29(2): 335-337.

Delizoicov, D., Angotti, J.A. \& Pernambuco, M.M. 2002. Ensino de Ciências: fundamentos e métodos. Cortez, São Paulo.

Edson-Chaves, B., Oliveira, R.D. de, Chikowski, R. dos S., Mendes, R.M. de S. \& Medeiros, J.B.L. de P. 2015. Ludo vegetal: uma nova alternativa para o ensino de Botânica. Revista Brasileira de Biociências 13(3): 194-200.

Freire, P. 1987. Pedagogia do oprimido. 17 ed. Paz e Terra, Rio de Janeiro.

Gonçalves, T.V.O. 2008. Feiras de ciências e formação de professores. In: A.C. Pavão \& D. Freitas (eds.). Quanta ciência há no ensino de ciências. EduFSCar, São Carlos, pp. 217-220.

Hartmann, A.M. \& Zimmermann, E. 2009. Feira de ciências: a interdisciplinaridade e a contextualização em produções de estudantes de ensino médio. In: Anais do $7^{\circ}$ Encontro Nacional de Pesquisa em Educação em Ciência - ENPEC, Florianópolis, p. 12.

Kinoshita, L. S., Torres, R.B., Tamashiro, J.Y. \& ForniMartins, E.R. 2006. A Botânica no ensino básico: relatos de uma experiência transformadora. RiMa, São Carlos.

Krasilchik, M. 2005. Prática de ensino de biologia. Editora da Universidade de São Paulo, São Paulo. 
Mancuso, R. 2000. Feiras de ciências: produção estudantil, avaliação, consequências. Contexto Educativo Revista Digital de Educación y Nuevas Tecnologias 6(1): 1-5.

Maturana, H. 2002. Emoções e linguagem na educação e na política. EdUFMG, Belo Horizonte.

Menezes, L.C., Souza, V.C. de, Nicomedes, M.P., Silva, N.A. da S., Quirino, M.R., Oliveira, A.G. de, Andrade, R.R.D. de Andrade \& Santos, B.A.C. dos. 2008. Iniciativas para o aprendizado de Botânica no ensino médio. In: Anais do $11^{\circ}$ ENCONTRO DE INICIAÇÃO À DOCÊNCIA, João Pessoa. Disponível em http://www. prac.ufpb.br/anais/xenex_xienid/xi_enid/prolicen/ANAIS/ Area4/4CFTDCBSPLIC03.pdf (acesso em 01-XII-2015).

Miranda-Neto, M.H., Bruno-Neto, R. \& Crisostimo, A.L. Sem data. Desenvolver projetos e organizar eventos na escola: uma oportunidade para pesquisar e compartilhar conhecimentos. Disponível em http://www.mudi.uem. br/index.php/textos-de-apoio/330-desenvolver-projetose-organizar-eventos-na-escola (acesso em 27-II-2015).

Nascimento, S.S. 2012. Protagonismo juvenil e inovação no desenvolvimento de projetos educativos. In: Moura, M.A. (org.). Educação científica e cidadania: abordagens teóricas e metodológicas para a formação de pesquisadores juvenis. EdUFMG, Belo Horizonte, pp.39-46.

Orvatti, L. \& Bueno, L.R. 2012. Investigações da Realidade de um Laboratório de Ciências em uma Escola da Rede Estadual de Ensino no Município de Maringá-PR. Revista Cesumar 17(2): 1-15.

Patti, Y.A., Montiel, J.M., Costa, K. da, Murgo, C.S., Silva, M.C.R. da, Bartholomeu, D. \& Campos, N.R. 2017. Percepção de professors do Ensino Médio acerca da motivação docente. Revista Psicopedagogia 34(103): 53-64.

Pliessnig, A.F. \& Kovaliczn, R.A. 2008. O uso de metodologias alternativas como forma de superação da abordagem pedagógica tradicional na disciplina de Biologia. Secretaria de Estado da Educação de Paraná Programa de Desenvolvimento Educacional (PDE - PR), Curitiba. Disponível em http://www.diaadiaeducacao. pr.gov.br/portals/pde/arquivos/1-4.pdf (acesso em 27II-2015).
Queiroz, S.F., Lira, F.L.C. \& Tonholo, J. 2017. Feira de Ciências no contexto da educação básica: tradição e inovação. In: $10^{\circ}$ Encontro Internacional de Formação de Professores, Aracajú, pp.1-15.

Rawitscher, F. 1937. Observações gerais do ensino de Botânica. Separata do Anuário da Faculdade de Filosofia, Ciências e Letras (1934-1935).

Salatino, A. \& Buckeridge, M. 2016. "Mas de que te serve saber Botânica?”. Estudos Avançados 30(87): 177-196.

Santana, D.G. de \& Ranal, M.A. 2004. Análise da germinação: um enfoque estatístico. Editora Universidade de Brasília, Brasília.

Sarnoski, E.A. 2014. Afetividade no processo ensinoaprendizagem. Revista de Educação do IDEAU 9(20): 1-12.

Silva, A.B.V. \& Moraes, M.G. 2011. Jogos pedagógicos como estratégia no ensino de morfologia vegetal. Biosfera 7(13): 1642-1652.

Silva, P.G.P., Cavassan, O. \& Seniciato, T. 2009. Os ambientes naturais e a didática das Ciências Biológicas. In: A.M. de A. Caldeira \& E.S.N.N. Araújo (orgs.). Introdução à didática. Escrituras, São Paulo, pp. 289-303.

Silva, J.R.S., Guimarães, F. \& Sano, P.T. 2016. Teaching of Botany in higher education: representations and discussions of undergraduate students. Revista Electrónica de Enseñanza de las Ciencias 15(3): 380393.

Souza, S.E. 2007. O uso de recursos didáticos no ensino escolar. In: $1^{\mathrm{o}}$ Encontro de Pesquisa em Educação, $4^{\mathrm{a}}$ Jornada de Prática de Ensino, $13^{\text {a }}$ Semana da Pedagogia UEM: "Infância de práticas educativas". Arquivos do Mudi. Maringá, pp. 110-114.

Tavares, R. 2007. Construindo mapas conceituais. Ciências e Cognição 2: 72-85.

Towata, N., Ursi, S. \& Santos, D.Y.A.C. 2010. Análise da percepção dos licenciandos sobre o 'ensino de Botânica na educação básica’. Revista da SBenBio 3: 1603-1612.

Yamazaki, S.C. \& Yamazaki, R.M. de O. 2006. Sobre o uso de metodologias alternativas para ensino aprendizagem de ciências. Disponível em http://fisica.uems.br/ profsergiochoitiyamazaki/t5p2metodologias.pdf (acesso em 20-IX-2015). 